\title{
Conceptualising inclusive education in Saudi Arabia through conversations with special education teachers
}

\section{Abstract}

In the last decade, inclusive education (IE) has become a trending topic in the kingdom of Saudi Arabia. This small-scale, qualitative Saudi study reports on how some teachers view IE in their country and whether students with a disability (autism) could be educated in mainstream schools. Individual semi-structured interviews were conducted and recorded using a smartphone. The analysis of interview data identified three themes related to IE and the concept of mainstream schooling for students with autism. Findings showed that the participants had some knowledge and understanding of IE. However, whether students with autism could be taught by general education teachers in mainstream schools reported mixed results. Some teachers spoke positively about the possibility, while others focused on existing barriers. These included the need for general education teachers to receive specialised training and professional learning in the form of authentic mentoring networks, training in special needs education to link theory with practice, and how the scarcity of classroom resources hampers quality educational experiences and outcomes for some students. These findings provide a starting point for further research into the emerging phase of IE in Saudi Arabia.

\section{Key words}

Inclusive education, autism spectrum disorder, Saudi Arabia, schooling, special education, teachers 


\section{Introduction}

Saudi Arabia is the largest of the sovereign states in Western Asia, with a population of approximately 33 million and more than half under the age of 25 years. While considered an arid country, it holds almost $20 \%$ of the world's petroleum, and has the largest economy of the Middle East. The country has large natural gas reserves, a significant gold supply, an agricultural sector, and a livestock industry. Saudi's commitment to economic reform through its Vision 2030, has included investment and initiatives in education. Professional learning through scholarships is available for teachers to study in international universities to improve their skills and competency. Initial teacher education (ITE) programs focus on the development of various pedagogies for instructing all students. ITE programs have been advanced to support government policy changes concerning inclusion, and some students with a disability now attend school alongside their same-aged peers (Kingdom of Saudi Arabia, n.d.). Education is considerably influenced by the cultural and religious characteristics of Saudi society (Alghamdi \& Ernest, 2019). "Educational policy emanates from Islam, which is the state belief, worship, ethics, law and life integrated system" (Smirnova, 2012), and the pillar of Saudi's modern education system. Educators have a religious and civic duty to ensure the Islamic concepts of equity, fairness and justice are enacted in their daily teaching.

\section{The Saudi education system}

Up until its unification in 1932, education was limited to a small number of schools located in a few demographic districts. They were schools for boys only but by 1960 , the General Presidency for Girls' Education (Ministry of Education, 2021) emerged. Since 2003, the Ministry of Education has been responsible for providing free primary, intermediate, secondary, and post-secondary education to all Saudi citizens, and in overseeing quality 
standards in private education (Saudi Arabian Cultural Mission, 2013). While most students are educated in the public system, by 2025 it is expected that $15 \%$ of students will be educated in private schools as a response to consumer demands for value for money private schooling (Strategic Gears Management Consultancy, 2018). Male and female students are taught in gender specific schools, with the core curriculum devoted to the practical application of Islam.

\section{Special needs education}

Prior to the late 1950 s, children with disabilities did not receive any formalised education, relying solely on parents for educational support. In 1960, the first special school for visually impaired boys opened, followed four years later by the opening of a special school for visually impaired girls. Since then, special needs schools have continued to emerge, develop, and grow, accommodating students with intellectual disabilities, autism, physical disabilities, and hearing impairments. As a result, Saudi Arabia has seen an increase in specialised programs and services for children with a disability, through its standard national curriculum which ensures all children have access to education, and through its implementation of government policy on inclusion.

A major objective of the Salamanca Statement and Framework for Action on Special Needs Education (UNESCO; United Nations Educational, Scientific and Cultural Organisation, 1994), was for students with a disability to attend their local school. Since that time, Saudi Arabia has entered a new era of special education by introducing education policies that encourage the integration of some special needs students into mainstream schools. In recent times, students with mild to moderate disabilities (e.g., intellectual disabilities, hearing and visual impairments, autism) who attend regular schools outnumber those receiving education in specialised facilities (Ministry of Education, 2012). 
Mainstreaming in Saudi Arabia is defined as "educating children with special educational needs in regular education schools and providing them with special education services" (Ministry of Education, 2002, p.8). This occurs in two ways: partial mainstreaming, consisting of self-contained classrooms within mainstream settings, and full mainstreaming where students with additional needs are educated in regular classrooms but withdrawn at specific times so they can access special education support programs. Not all schools offer mainstreaming, in fact the Regulatory Guide for Special Education (RGSE; Ministry of Education, 2016), states that there are in fact few regular schools offering support programs (e.g., special classes or counselling teacher services). Students with severe disabilities, including many with autism, are taught in special schools by teachers who hold special education qualifications.

\section{Students with autism}

According to Al-Farsi et al. (2011), the prevalence of autism in Saudi Arabia is unknown but in neighbouring Oman, statistics indicate that 0.14 per 1000 Omani children (aged 0-14 years) have autism. It is believed that there were up to 4200 children and adults with autism in Saudi Arabia by 2002 but recent statistics about children specifically, remain allusive (AlSalehi et al., 2009).

Despite the completion of some international papers about teacher attitudes to teaching students with autism, overall, there has only been a few studies published in this important area (Park \& Chitiyo, 2011). Of the paucity of research, teachers are generally positive about the inclusion of students with autism in mainstream classrooms (Leonard \& Smyth, 2020), with mainstreaming considered an effective and responsive teaching practice (McGillicuddy \& O’Donnell, 2014). However, the severity and pervasiveness of autism can be challenging and complexing for some teachers (Rodriguez et al., 2012). Considered a 
challenge globally, are communication problems such as introversion, obsessional behaviours, self-stimulation, and incoherency with language (Cassimos et al., 2015). Additionally, teachers have admitted that they have a limited knowledge and understanding of autism, are given few resources to enhance teaching and learning, receive limited paraprofessional support, and report that inappropriate and disruptive behaviours can be challenging to manage (Roberts \& Simpson, 2016).

Despite the affordances and constraints about teaching students with autism in mainstream classrooms, many developed nations have adopted IE and responsive teaching as a preferred teaching approach. Over the past 30 years, there has been a strong international focus on the rights for all students to learn resulting in an increase in the inclusion of students with disabilities attending mainstream schools (Amor et al., 2019). An international backdrop of standards and policies, e.g., The Convention on the Rights of Persons with Disabilities (UN; United Nations, 2006), The Dakar Framework for Action (UNESCO, 2000), A guide for ensuring inclusion and equity in education (UNESCO, 2017), and Inclusion and education: All means all (UNESCO, 2020), provide a representation of the widely available documents that seek to support the inclusion of all students in mainstream classrooms.

Specific to Saudi Arabia, Haimour \& Obaidat (2013) found that general education teachers have limited knowledge about students with autism. This is because they have received minimal if any training about teaching students with additional needs, resulting in a reluctance and hesitancy to teach special needs students. Most students with differing needs attend special schools where they do not have an opportunity to access an adapted or modified general education curriculum but do have access an individualised education program (IEP). There are also educational facilities that do not offer students with autism access to allied health professionals such as speech or occupational therapists, thereby limiting the essential support required for their unique needs. Students with autism need and 
deserve an education in a fully inclusive school environment, so they can be afforded and assured equity in their education.

\section{Inclusive Education in Saudi Arabia}

IE is an international approach to educational reform that sees quality teaching practices afforded to all students in age-appropriate classrooms, along with a response to the cultural, racial, sexual, religious, and academic diversity evident in today's classrooms. IE is multifaceted to adapt teaching methods, classroom organisation and teacher resources to ensure all learners, irrespective of their ability, are able to successfully participate and succeed academically in mainstream classrooms. As a philosophy, IE recognises that excluding any subgroup of student diversity is a violation of civil rights which breaches the principle of equal citizenship (UNESCO, 1994; Villa \& Thousand, 2005; Forlin, 2018). IE is more than just delivering academic content to all students but also supports the growth of every student and enable them to develop the skills and knowledge required for successful immersion into society (Katz \& Mirenda, 2002; Messiou, 2017). IE also involves the removal of special needs facilities, segregated classrooms, and a special needs model of learning (Anderson \& Boyle, 2019). IE is a comprehensive approach to meet the educational needs for all students (Shogren et al. 2017).

In Saudi Arabia, momentum and support for IE has slowly intensified in recent years, in part influenced by policy makers but also by considered debate about the unfolding of IE in educational sectors (Alharbi \& Mandesh, 2018). While schools in Western societies are moving away from inclusion viewed through a disability lens, how IE is enacted for students with disability and difference in the Saudi Arabia context is still evolving. There has been a dearth of research in this area to date (see Alquraini, 2011, 2012; Smith 2000), but also 
limited research exploring teacher attitudes to the inclusion of students with disability in Saudi mainstream schools.

\section{Saudi teacher attitudes to inclusion}

There has been growing interest in promoting IE in the Gulf and Middle East countries (Gaad, 2011), and while some students with mild and moderate cognitive disabilities attend a regular school, the preferred option is that they are educated in segregated, self-contained classrooms (Alquraini 2012). For many students with a disability, participation in Saudi mainstream classrooms remains allusive.

For IE in Saudi Arabia to be implemented effectively, a positive attitude by general education teachers about teaching children with difference, disability or diversity is crucial (Alnahdi et al., 2019). Recent studies have concluded that most general education teachers have a positive attitude towards students with diverse needs (Al-Ahmadi, 2009; Aljlamdah, 2014), although other researchers have suggested that not all teachers are confident to teach children with difference (Hakeem, 2009; Alquraini, 2011). Furthermore, limited physical and human support that is seen as essential for some students, poorly resourced classrooms, and a schools' organisational structure and culture, continue to challenge the implementation and success of IE in Saudi schools (Alruwaili, 2018). So, it is not surprising that some general education teachers feel underprepared to cater for students who have additional needs if they have not received the necessary teacher training or developed the requisite skills to do so.

\section{Context and the current study}

At this point in time, little is known about special needs teachers views about IE or their opinions about whether students with a disability could be educated in mainstream Saudi classrooms by general education teachers. This study explores IE from the context of six 
Saudi special needs primary school teachers who teach students with autism in a special needs school by answering the questions:

- How do special needs teachers view the progress of IE in Saudi Arabia?

- What key themes are identified by special needs teachers in transitioning students with autism to the regular classroom?

As this was the first study to be conducted with special needs teachers at a single setting, the research was exploratory in nature and small in scale.

\section{Method}

\section{Research site}

The setting for the study took place at a Ministry for Education primary and intermediate school specialising in the education of boys with autism. The school is situated in the eastern region of Saudi Arabia, approximately 300 kilometres from the capital, Riyadh. The school serves the entire oasis, with the majority of residents living within three main towns, while the rest of the population is scattered throughout a large number of small villages. Largely middle-class, the school is committed to providing excellence in education for the 49 enrolled students. The school serves boys only as per Saudi Arabia's gender specific schooling, consistent with Islamic norms in Saudi society, aged between 6-18 years. Each classroom accommodates 3 students per teacher, with many boys also diagnosed with an intellectual disability.

\section{Participants}

Ethical approval for the research was granted by the Ministry of Education-through the AlHasa Education Department. Recruitment of participants was undertaken initially through an introductory conversation by the second author, a Saudi national and his teaching colleagues. Prior to the research study, the second author had spent 12 months at an Australian university 
in Brisbane, Queensland, completing a School Emersion program. On his return to Saudi Arabia at the end of 2019, he was keen to complete a research project to explore his teacher colleagues' views on IE and their opinions about transitioning students with autism into mainstream classrooms.

Initially, the second author engaged in conversations with 15 fellow teaching colleagues about the research project and then more specifically about IE. After inviting 15 teachers to participate in the study, 6 teachers volunteered. Following their agreement, the second author arranged an interview time suited to each participant. Teachers ranged in age from 32 years to 38 years $(M=32.83)$ while teaching experience ranged from 8 to 13 years $(M=9.17)$. Demographic information pertaining to the teachers is summarised under pseudonyms in Table 1.

(Place Table 1 here)

\section{Data gathering}

Data were gathered using face-to face, semi-structured recorded interviews where each participant were asked to respond to pre-prepared, open-ended lead and prompt questions (as seen in Table 2). Interviews are a popular way to gather data for qualitative research (Jamshed, 2014). Using this method of interview in small-scaled studies, gave the opportunity for participants to express their viewpoints to a greater degree and allowed for the collection of in-depth data gathering. Interviews aimed for around 15 minutes duration. Each interview was recorded on the second author's mobile device, offering convenience and easy recording for transcribing purposes. Interviews occurred over a 3-month period (February 2019 to April 2019) at a mutually convenient time. Two days prior to the interview, participants were sent an email reminding them of the date and time of the interview and questions were included for their perusal in the email, as an attachment. A transcript of the interview was then emailed to each participant for verification of content 
(Creswell, 2014). Interviews were initially conducted in Arabic with the second author (an emerging English speaker) who then transcribed the recorded interviews into English. The lead author (a native English speaker) made slight adjustments to the transcripts to ensure the accuracy of the translations.

(Place Table 2 here)

\section{Fact coding process}

Following the completion of all interviews, the data were analysed following the phases of thematic analysis recommended by Braun and Clarke (2006). Thematic analysis is a commonly used method of analysis in qualitative research due to its flexibility (Braun \& Clarke, 2006). Qualitative data is coded to identify patterns across the data set in relation to the research questions. The flexibility of thematic analysis lay in the researcher's capacity to interpret the patterns and code emerging categories into developing themes (Braun \& Clarke, 2014).

The process consisted of six steps. First, each of the data sets were read twice by the two authors and initial ideas for codes were identified and highlighted. Second, the ideas were agreed on and manually coded. Third, after coding and collecting the data, information was sorted into developing themes. Fourth, themes were then reviewed and defined. The trustworthiness of the data set was strengthened by the two authors discussing and reaching commonality about the themes and thematic structure during the review phase of the coding process (Cho \& Trent, 2006). Fifth, the themes were then named. Finally, quotations were selected from the data using guidelines designed by Kvale and Brinkmann (2009) and are presented using pseudonyms. 


\section{Results and discussion}

Three key themes were identified during the analysis of the interview data: (1) knowledge and understanding of inclusive education; (2) advantages and constraints to mainstreaming students with autism; and (3) mainstream and special education teachers' roles - emerging and developing. The introductory theme indicated some basic knowledge and understanding of IE by the participants. The second theme highlighted the advantages and disadvantages to mainstreaming students with autism. The third theme identified the need for training and ongoing professional development for general education teachers if transitioning students with autism to mainstream schools were to occur.

\section{Knowledge and understanding of inclusive education}

The initial transcripts revealed that the teachers had some knowledge and conceptual understanding of IE. When asked for their perspectives, teachers indicated that IE is about "teaching in mainstream schools without discrimination" and about "consulting with parents, the teacher and the school administration." However, the teachers generally viewed IE from a disability perspective. For example, Teacher E indicated that IE was "a style of teaching that tries to assist ASD students to fully integrate with their peers," whereas Teacher F stated that IE is about "integrating ASD students in mainstream schools." Teacher D on the other hand, defined inclusion more broadly and from an equal opportunity perspective:

Educators try to integrate all students in one class, without excluding any student.

The most important goal of education is the consolidation between society members, and to give the students a chance to build their confidence in themselves and others, and IE helps students to accept all their peers with learning difficulties or without.

The participants varied capacity to define inclusion is not surprising as Ainscow et al. (2006) and more recently, Amor et al. (2019), suggest there are both broad and narrow 
definitions of the term. Wide-ranging definitions focus on how schools support every student, while narrower meanings focus specifically on students with a disability. Dyson (2014) states that a strong empirical evidence-base for inclusion is still lacking, while Florian (2014, p.286), posits that a "clear working definition of IE has thus far proved elusive." What is clear from these conversations, is that the teachers used the term 'integration' interchangeably with inclusion.

The teacher's knowledge about IE closely aligned with their self-identified teaching experiences. Half the participants considered that the ongoing practical skills they gained and learned from being a special needs teacher, provided a type of 'hands on' resource that assisted in their developing self-belief and understanding of inclusion. On the other hand, two teachers described the initial teacher education courses they completed at university provided them with some basic knowledge and understanding of inclusion. Researching IE in scholarly papers was also considered beneficial to expanding knowledge and understanding about inclusion for two of the participants, while one teacher stated that reading social media comments about inclusion had strengthened his knowledge. According to Dare et al. (2017), teachers have a significant responsibility for implementing and practicing inclusion in their classrooms, and despite IE developing as an innovative teaching pedagogy in Saudi Arabia, it is encouraging that this small group of special needs teachers have some knowledge and understanding about inclusion and its benefits for all students.

Finally, the teachers indicated that for IE to flourish in Saudi Arabia, educational resources to help facilitate learning processes were a necessary requirement in general classrooms. Interestingly, the teachers offered various ways in which they had acquired the kinds of resources that would be beneficial to support their teaching pedagogy. Two participants indicated that they had learned about a range of reliable evidenced-based resource materials in their ITE courses. On the other hand, three teachers proffered that 
through their own teacher practice they had created and collected a range of resources that they could easily match with individual student needs.

Ongoing training and professional development is a beneficial way to build special education teacher knowledge and understanding of IE and maintain ongoing conversation about the types of teaching approaches that are best suited to all students. This would assist teachers to identify any barriers evidenced by partial mainstreaming and segregated programs that are currently seen in most Saudi schools. This proposal of building essential skills and knowledge should begin at the pre-service level and is supported by the work of Alzahrani and Brigham (2017), who purport that there is a need for Saudi universities to be more accountable in their obligation to produce well-prepared and knowledgeable special education teachers.

\section{Advantages and constraints to mainstreaming students with autism [inclusion]}

As stated previously, most students with autism are educated in either special education institutes or in self-contained classes within Saudi mainstream schools. Inclusion as a philosophy would suggest that these students would be socially, behaviorally, and academically better advantaged if they were schooled along-side their same-aged peers in regular classrooms by general education teachers. Most of the participants spoke in commonality about the probable benefits for students with autism to be taught by general education teachers. Four teachers suggested that students with high-functioning autism could be well-suited to mainstream schooling because "they have no learning difficulties, are equal with other students and as such are able to learn in inclusive schools." On the other hand, another teacher reflected on the time that he had observed a student with autism who had been integrated into a mainstream classroom. He remembered that it was not a successful experience for the student. This was because he "was always alone and did not interact with others." In agreement, one of the other teachers also advised against mainstreaming for 
students with autism because "teachers and administrators in mainstream schools don't have enough experience, and ASD students need a teacher with qualifications in special education."

Teachers B, C, and E collectively recommended that if schools were inclusive, students with autism would find their schooling experience more positive because mainstream schools are "more appealing" than special schools because "it is easier to learn alongside your peers [who do not have a disability]." Further support of this proposal was identified by Teacher D who stated that:

The ASD student is like any other student, he is a normal except for some behaviours which are due to his [hyper] sensitivity. If the student is supported by his mainstream teacher, peers, and the school's counsellor, absolutely he 'll be successful. The evidence by international research, demonstrates there are ASD students who have achieved success in fields like music, maths, and art. Some of them can be teachers.

A clear area of concern by Teacher F was the necessity for students with autism to be educated by highly skilled and qualified teachers. "It is important that teachers are qualified to teach in inclusive schools. Qualifications would need to include training about autism and specific information about any student with autism who will be in the mainstream teacher's class." His opinion aligns with Aldabas (2015), who identified that professional development for general education teachers is necessary to prepare them for teaching in inclusive classrooms. Additionally, Teacher E highlighted that professional development and training about IE for general teachers must include:

Specific training programs. These training sessions must be in the same school in which the intended student will attend. Moreover, the teacher who will be teaching the student with autism must receive resources that will support the 
teaching/learning processes such as information and communication technology to be provided by the Ministry of Education.

Finally, while supportive of IE and the assimilation of students with autism into mainstream schools, Teacher A pointed out that "teachers and administrators in mainstream schools do not have enough experience [working with students with autism], and ASD students' need teachers with qualifications in special education expertise." While there are varied opinions evident, overall, most teachers have a positive mindset about the inclusion of students with autism in mainstream classrooms.

\section{Mainstream and special education teachers' roles - emerging and developing}

A constraining factor for IE to be successfully implemented in Saudi Arabian schools, is the specifically defined teaching roles of general education and special needs teachers in their relevant school contexts. Theoretically, IE is about the education for all students (Cologon, 2019) but what that could look like in Saudi Arabia is yet to be fully recognised and identified, according to our teachers.

Of concern for Teacher B and $\mathrm{F}$ was the training and up-skilling that general education teachers would require to enable them to teach students with autism effectively and skillfully. Teacher B stated that teachers must be "quality teachers" while teacher F conferred that it is:

Important to have qualified teachers, as well as [them] receiving ongoing information about autism, and information about each student who will be in his class. Unfortunately, this is not happening currently in Saudi's schools, and this is not appropriate for the [success of] inclusion.

As a positive aside, he added "that there is a lot of effort towards mainstreaming students with ASD from the higher authorities in the country, so I think there are some difficulties but if we prepare a training program for administrators, it is going to be easier to 
integrate ASD students." Likewise, Teacher C indicated that general education teachers would need to complete training in special education and suggested that "there are a lot of courses here in Saudi." The conundrum for him was "why these courses are not offered [currently] for those [general education] teachers." Teacher E was also in agreement to a requirement for general education teachers to receive specialised training by adding that this was the "responsibility for both teachers and the school principal."

Contrastingly, two teachers were not sure if students with autism could be taught effectively by general education teachers. For Teacher A, "if unqualified, teaching these students is difficult,"..... "even if the student learns in a mainstream school, I think it will fail because he [student] can't communicate. Educators might be able to teach an ASD student, but he will be alone without any friendships." Adding to this, Teacher D indicated that "some [mainstream] classrooms host up to 50 students. So, the teacher will face difficulties to control the classroom, focus on ASD students as well as the others." Furthermore, Teacher D stated that "the biggest challenge is acceptance. This is the key for ASD students. When he feels others [students without a disability] are respectful.... ASD students will be able to learn successfully." He finished by saying that "there would be no difficulties if mainstream teachers were qualified but....we need to decrease students to $10-12$ in the classroom." These assumptions by the teachers highlight the importance for all teachers to be adequately qualified and skilled. This could be achieved through training programs and professional learning opportunities that build teacher capacity to teach students with differing needs.

Overall, while some students with disabilities attend mainstream Saudi schools, this is largely dependent upon the nature and type of disability, and their individual academic needs (Al-Mousa, 2010). The six primary school specialist teachers indicated that there is still considerable work to be done to enable students with autism to transition to mainstream 
classrooms and be taught by general education teachers in Saudi Arabia. Specifically, they recommend specialised in-service training courses for general education teachers, educational supervisors, and administrators.

\section{Implications for the future}

The main purpose of this study was to explore six specialist autism spectrum disorder primary school teachers' views on IE, and whether students with autism could be transitioned into mainstream classrooms. From a research and practice perspective, there is still some way to go before IE will be fully endorsed and implemented in all Saudi schools. Initially, it is important to provide direction to teachers and school principals to enable them to build learning capacity about IE and the benefits of teaching in multi-ability classrooms so that all students can receive the learning they require to academically achieve. According to AlMousa (2010), mainstreaming is considered to be the most effective way to educate students with a disability in Saudi Arabia as "regular schools are the natural place for the development of accurate concepts about the potentialities and capabilities of all children" (p. 49).

Given the current status of IE in Saudi Arabia, it is recommended that universities with ITE programs provide the essential knowledge and skills required for new graduate teachers to successfully teach in multi-ability classrooms (Hopkins et al., 2018). A further recommendation is for universities with post-graduate teacher education courses to provide special needs teachers with training as mentors and professional inclusive coaches so that they can provide the necessary knowledge and skills in IE to their colleagues. Universities in Saudi Arabia could introduce courses in differentiated learning experiences at the undergraduate and post-graduate level. Differentiation is a responsive approach to teaching in mainstream classrooms that enables general teachers to be student-centred, address individual student's needs and interests, and produce successful academic and social outcomes for all 
students (Author 2021; Tomlinson, 2014). Likewise, co-teaching is increasingly being considered as ways for general education and special needs teachers to blend their pedagogical expertise in a single classroom space to deliver instruction that meets the learning requirements of all class members (Friend et al., 2010). Up-skilling, training and using these teaching practices could provide some of the necessary skills for IE to be successful in Saudi schools.

It is important for schools to adopt a more positive approach to promoting education for all students and to remove existing barriers that do not promote IE such as segregated, self-contained resource classrooms and special schools. It is also important for school principals to foster an IE culture in their schools so that all members of the school community (students, teachers, school administrators, parents, and the wider community) experience what it is like to be part of a school that welcomes all students, that is, those with and without disability, difficulty, or difference.

A culture of professional learning that is enabled through commitment realised by strong school leadership, is also recommended. The need for ongoing skill development and professional learning opportunities through workshops, in-school mentoring and coaching by special needs educators, guided reflection, and teacher observations will ensure all teachers are exposed to IE as a teaching philosophy beneficial for all students (Jarvis et al., 2016). It is also imperative that school leaders demonstrate authentic school leadership so that every educator is well-prepared to teach in multi-ability classrooms. Finally, for IE to be fully practiced in Saudi schools, general teachers require time to effectively collaborate with special needs teachers, prepare for, and trial IE in their classrooms. 


\section{Conclusion}

This study has highlighted that policy makers in Saudi Arabia have come some way to supporting and implementing IE in schools. However, from listening to the six primary specialist educators, there are both advantages and constraints to IE and its evolving progress. As such, there still some way to go before Saudi Arabia fully includes students with disabilities into mainstream classrooms that are evidenced today in many schools across the globe. The conversations by the six specialist teachers allowed opportunity to contribute to a topic that is somewhat polarising for some and confusing for others but provided open and honest perspectives about current IE practice in Saudi Arabia. 
Notes

Acknowledgements and Declaration of Conflicting Interests

There are no conflicting interests with this manuscript.

\section{Funding}

The authors received no financial support for the research, authorship, and/or publication of this article. 


\section{References}

Ainscow, M., Booth, T., \& Dyson. A. (2006). Improving schools, developing inclusion. Routledge.

Al-Ahmadi, N. A. (2009). Teachers' perspectives and attitudes towards integrating students with learning disabilities in regular Saudi public schools. (Unpublished doctoral dissertation). Athens: Ohio University.

Aldabas, R. A. (2015). Special education in Saudi Arabia: History and areas for reform. Creative Education, 6, 1158-1167.

Al-Farsi, Y. M., Al-Sharbati, M., Al-Farsi, O. A., Al- Shafaee, M. S., Brooks, D. R., \& Waly, M. I. (2011). Prevalence of autism in Oman. Journal of Autism and Developmental Disorders 41, 821-825.

Alghamdi, A. A., \& Ernest, G. M. (2019)._Teachers' beliefs about developmentally appropriate practices in Saudi Arabia. International Journal of Childcare and Educational Policy, $13,1-16$.

Alharbi, A. \& Madhesh, A. (2018). Inclusive education and policy in Saudi Arabia. International Journal of Education Research and Reviews, 6, 946-956.

Aljlamdah, F. (2014). Attitudes of primary and middle school teachers and administrators about the integration of students with special needs in regular schools in Kingdom of Saudi Arabia. Special Education Journal, 9, 155-193.

Alnahdi, G. H., Saloviita, T., \& Elhadi, A. (2019). Inclusive education in Saudi Arabia and Finland: Pre-service teachers' attitudes. Support for learning, 34, 71-85.

Alquraini, T. (2011). Special Education in Saudi Arabia; Challanges, Perspectives, Future Possibilities. International Journal of Special Education, 25, 139-147.

Alquraini, T. (2012). Teachers' Perspectives of Inclusion of the Students with Severe Disabilities in Elementary Schools in Saudi Arabia. Doctoral dissertation. Ohio University.

Al-Mousa, N. A. (2010). The experience of the kingdom of Saudi Arabia in mainstreaming students with special educational needs in public schools. The Arab Bureau of Education for the Gulf States: Riyadh, Saudi Arabia.

Alruwaili, M. A. (2018). Obstacles facing implementation of inclusion of SEN students in mainstream secondary schools in Saudi Arabia. Scientific Research Journal in Education, 19, 665-684.

Al-Salehi, S. M., Al-Hifthy, E. H., \& Ghaziuddin, M. (2009). Autism in Saudi Arabia: Presentation, clinical correlates and comorbidity. Transcultural Psychiatry, 46, 340347. 
Alzahrani, A., \& Brigham, F. (2017). Evaluation of special education preparation programs in the field of autism spectrum in Saudi Arabia. International Journal of Special Education, 32, 746-766.

Amor, A. M., Hagiwara, M., Shogren, K. A., Thompson, J, R., Verdugo,M, V., Burke, K. M., \& Aguayo, V. (2019). International perspectives and trends in research on inclusive education: a systematic review. International Journal of Inclusive Education, 23, 12771295 ,

Anderson, J., \& Boyle, C. (2019). Looking in the mirror: reflecting on 25 years of inclusive education in Australia. International Journal of Inclusive Education, 23, 796-810.

Authors (2021).

Braun, V., \& Clarke, V. (2006). Using thematic analysis in psychology. Qualitative Research in Psychology, 3, 77-101.

Cassimos, D. C., Polychronopoulou, S. A., Tripsianis, G. I., \& Syriopoulou-Delli, C. K. (2015). Views and attitudes of teachers on the educational integration of students with autism spectrum disorders. Developmental Neurorehabilitation, 18, 241-251.

Cho, J., \& Trent, A. (2006). Validity in qualitative research revisited. Qualitative Research, 6, 319-340.

Cologon, K. (2019). Inclusive education isn't dead, it just smells funny. Journal of Education Policy, 34, 742-743.

Creswell, J. W. (2014). Educational research: Planning, conducting, and evaluating quantitative and qualitative Research $\left(4^{\text {th }}\right.$ ed.). Pearson.

Dare, L., Nowicki, E., \& Felimban, H. (2017). Saudi children's thoughts on inclusive education. International Journal of Inclusive Education, 29, 286-543.

Dyson, A. (2014). A response to Nilholm and Göransson. European Journal of Special Education, 29, 281-282.

Florian, L. (2014). What counts as evidence of inclusive education? European Journal of Special Education, 29, 286-294.

Forlin, C. (2018). Teacher education and inclusion in the Asia Pacific region. Oxford Research Encyclopedia of Global Perspectives on Teacher Education. Oxford University Press.

Friend, M., Cook, L., Hurley-Chamberlain, D., \& Shamberger, C. (2010). Co-teaching: An illustration of the complexity of collaboration in special education. Journal of Educational and Psychological Consultation, 20, 9-27.

Gaad, E. (2011). Inclusive Education in the Middle East. Routledge.

Haimour, A. I., \& Obaidat, Y. F. (2013). School teachers' knowledge about autism in Saudi Arabia. World Journal of Education, 3, 45-56. 
Hakeem, A. A. (2009). Attitudes of teachers of primary and middle schools in Mecca towards the policy of inclusion in public schools: comparative study. College of Education Journal, 79, 188-214.

Hopkins, S. L., Round, P. N., \& Barley, K. D. (2018). Preparing beginning teachers for inclusion: Designing and assessing supplementary fieldwork experiences. Teachers and Teaching, 24(8), 915-930.

Jamshed, S. (2014). Qualitative research method-interviewing and observation. Journal of Basic and Clinical Pharmacy, 5, 87-88.

Jarvis, J. M., Bell, M., \& Sharp, K. (2016). Leadership for differentiation: An appreciative inquiry of how educational leadership shapes pedagogical change. Leading and Managing, 22, 75-91.

Katz, J., \& Mirenda, P. (2002). Including students with developmental disabilities in general education classrooms: educational benefits. International Journal of Special Education, $17,14-24$.

Kingdom of Saudi Arabia. (n.d.). Human capital development program. Vision 2030. https://vision2030.gov.sa/en/programs/HCDP

Kvale, S., \& Brinkmann, S. (2009). Learning the craft of qualitative research interviewing. Sage.

Leonard, M., \& Smyth, S. (2020, early online). Does training matter? Exploring teachers' attitudes towards the inclusion of children with autism spectrum disorder in mainstream education in Ireland. International Journal of Inclusive Education, 1-15.

McGillicuddy, S., \& O’Donnell, G. M. (2014). “Teaching students with autism spectrum disorder in mainstream post-primary schools in the republic of Ireland." International Journal of Inclusive Education, 18, 323-344.

Messiou, K. (2017). "Research in the field of inclusive education: time for a rethink?" International Journal of Inclusive Education, 21, 146-159.

Ministry of Education. (2021). Premium education to build universally competitive knowledge society. https://www.moe.gov.sa/en/default.aspx

Ministry of Education. (2002). The document of roles and regulation for special education institutes and programs. General administration of special education. Riyadh, Saudi Arabia.

Ministry of Education. (2012). Statistical Manual of Institutes and Special Education Programs for the Academic Year 2012/2013. Riyadh, Saudi Arabia.

Ministry of Education. (2016). "Regulatory Guide for Special Education (RGSE)." https://departments.moe.gov.sa/SPED/Documents/RegulatoryGuide.pdf 
Park, M., \& Chitiyo, M. (2011). An examination of teacher attitudes towards children with autism. Journal of Research in Special Educational Needs, 11, 70-78.

Roberts, J., \& Simpson, K. (2016). A review of research into stakeholder perspectives on inclusion of students with autism in mainstream schools. International Journal of Inclusive Education, 20, 1084-1096.

Rodriguez, I. R., Saldana, D. \& Moreno, J. F. (2012). Support, Inclusion, and Special Education Teachers' Attitudes toward the Education of Students with Autism Spectrum Disorders. Autism Research and Treatment, 1-8.

Saudi Arabian Cultural Mission. (2013). "Background educational system in Saudi Arabia." https://www.sacm.org/ education.aspx.

Shogren, K. A., Wehmeyer, M. L., \& Shing, N. N. (2017). Handbook of Positive Psychology in Intellectual and Developmental Disabilities: Translating Research into Practice. Springer.

Smirnova, M. (2012). In C. L. Glenn \& J. De Groof (Ed.), Balancing freedom, autonomy and accountability in education (pp. 215-225). Wolf Legal Publishers.

Smith, M. G. (2000). Attitudes of middle school teachers in Tennessee toward inclusion for students with disabilities in the regular education classrooms. Unpublished doctoral dissertation, University of Memphis, Tennessee.

Strategic Gears Management Consultancy. (2018). Growth potential of private education in Saudi Arabia. https://www.strategicgears.com/wp-content/uploads/2018/09/GrowthPotential.pdf

Tomlinson, C. A. 2014. The differentiated classroom: Responding to the needs of all learners ( $2^{\text {nd }}$ ed.). Association for Supervision \& Curriculum Development.

UNESCO. (1994). The Salamanca statement and framework for action on special needs education. http://www.unesco.org/education/pdf/SALAMA_E.PDF

UNESCO. (2000). The Dakar Framework for Action. https://www.right-toeducation.org/sites/right-to-education.org/files/resourceattachments/Dakar_Framework_for_Action_2000_en.pdf

UNESCO. (2017). A guide for ensuring inclusion and equity in education. https://unesdoc.unesco.org/ark:/48223/pf0000248254

UNESCO. (2020). Inclusion and education: All means all. https://en.unesco.org/gemreport/report/2020/inclusion

United Nations. (2006). Convention on the Rights of Persons with Disabilities. https://www.un.org/development/desa/disabilities/convention-on-the-rights-of-personswith-disabilities.html 
Villa, R. A., \& Thousand , J. S. (2005). Creating an Inclusive School. Association for Supervision \& Curriculum Development. 